\title{
SOCIOECONOMIC STATUS, HEALTH RELATED BEHAVIOUR, AND SELF-RATED HEALTH OF CHILDREN LIVING IN ROMA SETTLEMENTS IN HUNGARY
}

\author{
Attila Sárváry', Zsigmond Kósa², Renáta Erdei Jávorné², Anikó Gyulai², Péter Takács ${ }^{3}$, János Sándor ${ }^{4}$, Andrea \\ Sárváry ${ }^{5}$, Ágnes Németh ${ }^{6}$, Réka Halmai ${ }^{1}$, Róza Ádány ${ }^{7}$ \\ ${ }^{1}$ Department of Nursing Science, Faculty of Health, University of Debrecen, Nyíregyháza, Hungary \\ ${ }^{2}$ Department of Health Visitor Methodology and Public Health, Faculty of Health, University of Debrecen, Nyiregyháza, Hungary \\ ${ }^{3}$ Department of Health Informatics, Faculty of Health, University of Debrecen, Nyíregyháza, Hungary \\ ${ }^{4}$ Division of Biostatistics and Epidemiology, Department of Preventive Medicine, Faculty of Public Health, University of Debrecen, Debrecen, \\ Hungary \\ ${ }^{5}$ Department of Psychology, Faculty of Health, University of Debrecen, Nyíregyháza, Hungary \\ ${ }^{6}$ National Institute of Child Health, Budapest, Hungary \\ ${ }^{7}$ Department of Preventive Medicine, Faculty of Public Health, University of Debrecen, Debrecen, Hungary
}

\section{SUMMARY}

Objective: The poor health of Roma is well documented, but there is only limited data regarding the health of Roma children. The aim of this study was to describe the socioeconomic status, health related behaviour, and health of children living in segregated Roma settlements, and to compare the data with that of non-Roma children.

Methods: In March-April of 2011, a cross-sectional questionnaire-based survey among 11-year-old (211 boys and 252 girls) and 13-year-old (205 boys and 247 girls) children living in Roma settlements was performed (response rate: 91.5\%). These data were compared with data from the Health Behaviour in School-Aged Children (HBSC) survey carried out in 2009/2010.

Results: The parents of Roma children were substantially less educated and less likely to be actively employed, and Roma children reported lower material welfare than non-Roma ones. The prevalence of consuming sweets and soft drinks at least 5 times per week was 1.5-2 times higher among Roma children. The prevalence of regular intense physical activity was higher at the age of 13 years among Roma boys, while physical inactivity was substantially higher in both age groups among Roma girls. Almost one quarter of Roma children and approximately $14 \%$ of non-Roma children had tried smoking at the age of 11. More Roma boys tried alcohol at the age of 11 than non-Roma ones. One in ten Roma children was obese in both age groups. The self-rated health status of Roma children was worse than that of non-Roma children.

Conclusions: Children living in Roma settlements reported poorer socioeconomic conditions, higher consumption of sweets and soft drinks, earlier smoking and alcohol initiation, and worse self-rated health, but with some exceptions do not differ in fruit or vegetable consumption and BMI from general child population. To promote health of children living in Roma settlements, a multi-sector approach, special health education, plus social and health promotion programmes are needed.

Key words: health behaviour, Roma children, prevalence

Address for correspondence: A. Sárváry, Department of Nursing Science, Faculty of Health, University of Debrecen, Sóstói u. 2-4, 4400 Nyiregyháza, Hungary. E-mail: sarvary.attila@foh.unideb.hu

https://doi.org/10.21101/cejph.a4726

\section{INTRODUCTION}

Roma are the largest ethnic minority group, and depending on the source (many Roma do not indicate themselves as Roma in official censuses, while Roma organizations frequently overestimate their number) there are an estimated 11-15 million individuals in the European Region (1). The number of Roma is highest in Romania (approximately $1.2-2.5$ million, $8.3 \%$ of the population) and Bulgaria $(700,000-800,000,10.3 \%$ of the population), while in Hungary the Roma population accounts for approximately $7.05 \%$
$(400,000-1,000,000)$ of the total population, and their number is continuously increasing (1). It is well known that the health status of an individual is determined not only by genetics, physical environment and the access and use of the health care system, but also by the social environment (2-4). In most of central, eastern and southern Europe, the Roma population lives in poor conditions (e.g., poorly-equipped and crowded houses without tap water, heating or electricity), and in some areas in segregated settlements $(5,6)$. The proportion of Roma population living in segregated conditions varies in different countries, e.g. in Hungary it is $20-26 \%$ (4). 
Nevertheless, the European Union will need to assess the Roma population, especially their health problems, because of their increasing population, which is occurring mainly in the post-communist countries. The severity of this problem was recognized by Hungary and other central and eastern European countries before they joined the European Union, and an international regional conference was held in 2003 in Budapest entitled "Roma in an Expanding Europe: Challenges for the Future." This launched the development of a European Union-wide 10-year programme called the Decade of Roma Inclusion 2005-2015 (7). In Hungary, several programmes were compiled and launched that aimed to improve their housing and environment, as well as to sell off the Roma settlements and to promote their lifestyle. A new long-lasting comprehensive programme entitled "Hungarian National Social Inclusion Strategy - Extreme Poverty, Child Poverty, Roma (2011-2020)" was prepared in accordance with the document "An EU Framework for National Roma Integration Strategies up to 2020" that was published by the European Commission (1). Although many policy initiatives have been designed over the past two decades to tackle Roma's adverse social conditions in central and south-eastern Europe, they have had limited success $(8,9)$.

Although morbidity and mortality data regarding the health of Roma are often insufficient due to missing records on ethnic status, some recent studies from Bulgaria and Serbia have shown that their mortality is significantly higher compared to the general population or to other ethnic/religious groups, furthermore, excess mortality has been observed for every cause of death examined $(10,11)$. These results have strengthened the estimation that life expectancy for Roma is shorter compared to the general population (12). The discrepancy in morbidity and mortality can be explained by the socioeconomic status and behaviour of people living in Roma settlements in Hungary $(13,14)$.

The gap between the health status of Roma and non-Roma populations can be observed even in early childhood. Preterm birth and/or low birth weight, as well as infant mortality, are higher in the Roma population than in the general population (15-17).

A comprehensive survey that takes complex lifestyle factors into consideration in Roma children is rare in the literature (18-21). Therefore, the aim of our study was to describe the socioeconomic status, health related behaviour, and self-rated health of 11 and 13-year-old children living in Roma settlements. Using the methodology of Health Behaviour in School-Aged Children Study (22) provides a unique opportunity to compare selected characteristics with those of peers from the general child population.

The Health Behaviour in School-Aged Children Study (HBSC) is a collaborative cross-national study launched in 1983 by the World Health Organization (WHO), which has been conducted in an increasing number of countries (43 at last count) every 4 years and collects data on the health, well-being, social environment and health behaviours of 11, 13 and 15 years old boys and girls across the WHO European Region and North America.

\section{MATERIALS AND METHODS}

We compared data from two surveys, conducted one year apart, which were based on the same internationally recognized methodology (23). The first was the HBSC survey of 2009/2010 including the school-aged population of Hungary (24). In Hungary the survey was led by the National Institute of Child Health (OGYEI - Hungarian acronym) in cooperation with the World Health Organization (25). The target populations were young people aged 11, 13 and 15, but in Hungary it was extended to schoolchildren aged 17. Cluster samplings were used where one sampling unit was a school class. In Hungary, the planned sampling frame was 2,000 pupils per age group. The response rate was $82.6 \%$, a total of 8,114 pupils filled in the questionnaires and 8,096 (3,957 boys and 4,139 girls) were evaluated (25). The research was approved by the Scientific and Research Ethics Committee of the Medical Research Council. A detailed description of the study methodology is described elsewhere (26).

The second targeted survey (Roma HBSC) took place in the north-eastern part of Hungary with the highest Roma population density. This survey was conducted by our research team in March-April of 2011 among school-aged children living in segregated settlements in the following three counties: BorsodAbaúj-Zemplén, Hajdú-Bihar and Szabolcs-Szatmár-Bereg.

\section{Sampling and Data Collection among School-aged Population Living in Roma Settlements}

Between 2001 and 2003, a detailed environmental survey was conducted in Hungary in the above mentioned three counties with the aim of identifying settlements (whose inhabitants are almost exclusively Roma) and ascertaining the number of people living in these settlements (4). Settlements identified in this environmental survey with capitation of at least 100 people formed the basis of the sampling.

The sampling frame of the research was provided by the number of pupils with mean ages of 11.5 and 13.5 (3,781 students) who lived in Roma settlements in three counties. The planned sample size was 1,000 pupils. Data collection was carried out in primary schools using a method similar to the HBSC research method.

During the first stage of sample selection we identified the schools where the number of pupils living in Roma settlements was high. An informative letter was sent to the school principals requesting their permission to conduct data collection. One thousand pupils were selected by a multistage, stratified (by counties and age groups) and random sampling procedure in these schools. Thus far, 915 (91.5\%) questionnaires have been returned, and we have analysed the data from 46311 -year-old (211 boys and 252 girls) and 452 13-year-old (205 boys and 247 girls) pupils living in Roma settlements.

\section{Questionnaire and Data Collection}

We used the same questionnaires that were used in the 2009/2010 HBSC Hungarian national survey for children with mean ages of 11.5 and 13.5 years.

The questionnaire covers the following main subjects: demographic factors, social background and context, subjective health outcomes, and health behaviours including risk behaviours.

Questionnaires were filled either by pupils individually or in case of need via assisted administration by a trained interviewer in groups with a maximum of 3 pupils. 
We sent an informative letter to the parents of the involved children to inform them about the purpose of the research and asked them to give their passive consent. The research was approved by the Regional and Institutional Ethics Committee of the University of Debrecen and by the Scientific and Research Ethics Committee of the Medical Research Council.

\section{Measurements}

We considered 11-year-old pupils to be those who were born between January 1, 1999 and December 31, 2000 and considered 13-year-olds to be those who were born between January 1, 1997 and December 31, 1998.

To describe the socioeconomic status of the pupils we analysed the following 4 factors: the educational status of their parents (primary education only versus university/academy); the employment status of the parents (both mother and father actively employed); and the material welfare of the family, which was measured by a summed score of the Family Affluence Scale (27) and then defined as low ( $0-3$ points), medium (4-6 points) and high (7-9 points). The subjective rating of family wealth was measured by using the question 'How well off do you think your family is?' and the answer was rated as low (very bad or bad), average, or high (very good or good).

Eating habits were described by the consumption of fruits, vegetables, sweets and soft drinks in three categories: students who consumed them never or less than once a week, those who consumed them irregularly, and those who consumed them at least 5 times a week (regular).

Physical activity was analysed by the frequency of intense exercises performed out of school only. We formed the following three categories: pupils who exercised intensely regularly (at least 4 times per week) in addition to the physical education (PE) lessons at school; students who more rarely exercised but who exercised at least once a week; and those who never exercised or exercised intensely once per month only.

To determine the nutritional status of pupils based on their reported height and weight, we used the body mass index (BMI). Categories (underweight, normal, overweight, and obese) were classified according to the reference BMI-for-age tables suggested by the $\operatorname{WHO}(28,29)$. We considered median BMI between -2SD and +1 SD for boys and girls as normal (for 11 years old boys $16.91-19.20 \mathrm{~kg} / \mathrm{m}^{2}$, for 11 years old girls $17.21-19.90 \mathrm{~kg} / \mathrm{m}^{2}$; and for 13 years old boys $18.21-20.80 \mathrm{~kg} / \mathrm{m}^{2}$, for 13 years old girls $18.81-21.80 \mathrm{~kg} / \mathrm{m}^{2}$ ), the $\leq-2 \mathrm{SD}$ as underweight (for 11 years old boys $\leq 16.90 \mathrm{~kg} / \mathrm{m}^{2}$, for 11 years old girls $\leq 17.20 \mathrm{~kg} / \mathrm{m}^{2}$; and for 13 years old boys $\leq 18.20 \mathrm{~kg} / \mathrm{m}^{2}$, for 13 years old girls $\leq 18.80 \mathrm{~kg}$ / $\mathrm{m}^{2}$ ), between $\geq+1 \mathrm{SD}$ and $\leq+2 \mathrm{SD}$ as overweight (for 11 years old boys $19.21-22.50 \mathrm{~kg} / \mathrm{m}^{2}$, for 11 years old girls $19.91-23.70 \mathrm{~kg}$ / $\mathrm{m}^{2}$; and for 13 years old boys $20.81-24.80 \mathrm{~kg} / \mathrm{m}^{2}$, for 13 years old girls $21.81-26.20 \mathrm{~kg} / \mathrm{m}^{2}$ ) and $>+2 \mathrm{SD}$ as obese (for 11 years old boys $\geq 22.51 \mathrm{~kg} / \mathrm{m}^{2}$, for 11 years old girls $\geq 23.71 \mathrm{~kg} / \mathrm{m}^{2}$; and for 13 years old boys $\geq 24.81 \mathrm{~kg} / \mathrm{m}^{2}$, for 13 years old girls $\geq 26.21 \mathrm{~kg} / \mathrm{m}^{2}$ ).

Risk behaviours were examined using the frequency of trying tobacco, the frequency of smoking (regular smokers were those who smoked daily or more than once a week; irregular smokers were those who smoked once a week or less than weekly - occasionally). We also measured the frequency of trying alcohol and the occurrence of drunkenness.
Self-rated health was analysed with the question "What do you think of your health condition?" Three categories were made: excellent or good, fair, and poor.

\section{Statistical Analysis}

Data were stratified by gender in the two age groups. The following statistical parameters and procedures were used in the analysis: prevalence and distributions with $95 \%$ confidence intervals (CIs). Data were analysed by using the SPSS 15.0 (SPSS Inc., Chicago, IL, USA) software package.

\section{RESULTS}

\section{Socioeconomic Characteristics}

The parents of Roma children were substantially less educated and less likely to be actively employed compared to the sample from the general population (Table 1). Among the parents of Roma children, the proportion of actively employed fathers was substantially higher than that of mothers. The Roma children reported lower material welfare measured by both the objective scale - Family Affluence Scale (FAS) and the subjective perception of family wealth. The proportion of Roma families belonging to the low FAS category was more than twice as high, and their proportion in the lowest category of subjective financial status was more than four times higher than that of the families in the national sample.

\section{Eating Habits, Physical Activity, BMI}

The eating habits of Roma children were very unfavourable regarding the consumption of sweets and soft drinks (Table 2). Although approximately two-thirds of children in both age groups and in both populations consumed fruit every day, more Roma girls at age 11 reported lower fruit consumption. A large difference was observed between two population groups in the consumption of sweets and soft drinks. Among Roma children, the prevalence of regular (at least 5 times per week) consumption of sweets ( 11 years old boys $66.5 \%, 11$ years old girls $71.4 \% ; 13$ years old boys $69.5 \%, 13$ years old girls $75.7 \%$ ) and soft drinks (11 years old boys $77.9 \%$, 11 years old girls $71.2 \%$; 13 years old boys $80.3 \%$, 13 years old girls $80.7 \%$ ) were one and a half and two times higher among children in the general population. In the Roma sample, more girls than boys reported regular sweets consumption.

Approximately half of the children in both populations (except the girls) reported performing intense physical activity regularly (daily or 4-5 times per week), and in both populations and in both age groups boys were more likely to report this than girls. Regular intense physical activity was more prevalent among the Roma boys aged 13, while among the Roma girls physical inactivity was higher in both age groups compared with non-Roma children.

Taking the BMI categories, the prevalence of obesity was higher among Roma girls in both age groups than in the general population. Approximately $20 \%$ of Roma children and children in the general population were overweight at age 11 years. Moreover, at both ages, one in 10 Roma children was obese. 
Table 1. Socioeconomic characteristics of children living in Roma settlements (Roma Children Health Survey 2011) and in general child population (Health Behaviour in School-aged Children - HBSC 2009/2010) in Hungary

\begin{tabular}{|c|c|c|c|c|}
\hline \multirow{3}{*}{ Characteristics } & \multicolumn{2}{|c|}{ Children living in Roma settlements } & \multicolumn{2}{|c|}{ General child population } \\
\hline & 11 years & 13 years & 11 years & 13 years \\
\hline & $(n=463)$ & $(n=452)$ & $(n=1,873)$ & $(n=1,905)$ \\
\hline \multicolumn{5}{|l|}{ Education } \\
\hline Only primary education of parents (8 years) & $49.4^{\mathrm{a}}(46.0-52.7)$ & $52.7^{\mathrm{a}}(49.3-56.1)$ & $11.5^{\mathrm{a}}(9.2-11.5)$ & $11.6^{a}(10.2-12.4)$ \\
\hline Vocational school & $11.6^{\mathrm{a}}(9.3-14.2)$ & $12.1^{\mathrm{a}}(9.9-14.8)$ & $22.4^{\mathrm{a}}(22.5-26.5)$ & $30.5^{\mathrm{a}}(28.8-32.3)$ \\
\hline Secondary education & $2.6^{\mathrm{a}}(1.6-4.1)$ & $4.0^{\mathrm{a}}(2.7-5.8)$ & $21.9^{a}(20.0-23.8)$ & $25.1^{\text {a }}(23.5-26.8)$ \\
\hline University education & $0.6^{a}(0.3-1.5)$ & $0.6^{a}(0.2-1.4)$ & $25.5^{\mathrm{a}}(22.3-25.5)$ & $25.7^{\mathrm{a}}(23.9-26.9)$ \\
\hline \multicolumn{5}{|l|}{ Employment } \\
\hline Actively employed fathers & $37.6^{a}(33.1-42.2)$ & $43.3^{\mathrm{a}}(38.7-48.6)$ & $84.3^{\mathrm{a}}(82.6-85.9)$ & $82.1^{\mathrm{a}}(80.3-83.8)$ \\
\hline Actively employed mothers & $15.0^{\mathrm{a}}(11.9-18.7)$ & $18.8^{a}(15.4-22.8)$ & $72.0^{\mathrm{a}}(69.9-74.0)$ & $72.4^{\mathrm{a}}(70.3-74.4)$ \\
\hline \multicolumn{5}{|l|}{ Family Affluence Scale (FAS) } \\
\hline Low FAS & $71.7^{\mathrm{a}}(67.3-75.7)$ & $70.9^{\mathrm{a}}(66.4-75.0)$ & $31.1^{\mathrm{a}}(29.0-33.3)$ & $30.3^{a}(28.3-32.5)$ \\
\hline Middle FAS & $24.6^{a}(20.8-28.9)$ & $22.4^{\mathrm{a}}(18.7-26.6)$ & $50.5^{\mathrm{a}}(48.2-52.8)$ & $51.3^{\mathrm{a}}(49.0-53.6)$ \\
\hline High FAS & $3.7^{\mathrm{a}}(2.2-6.0)$ & $6.7^{\mathrm{a}}(4.7-9.6)$ & $18.4^{\mathrm{a}}(16.7-20.3)$ & $18.4^{a}(16.7-20.2)$ \\
\hline \multicolumn{5}{|l|}{ Perceived financial status } \\
\hline Very bad or bad & $17.4^{\mathrm{a}}(14.1-21.2)$ & $14.9^{\mathrm{a}}(11.8-18.6)$ & $2.4^{\mathrm{a}}(1.7-3.14)$ & $3.6^{\mathrm{a}}(2.78-4.51)$ \\
\hline Average & $30.4(26.3-34.8)$ & $47.3(42.7-52.1)$ & $34.0(31.9-36.2)$ & $53.4(51.1-55.7)$ \\
\hline Very good or good & $52.2^{\mathrm{a}}(47.6-56.9)$ & 37.7 (33.3-42.5) & $63.7^{\mathrm{a}}(61.4-65.6)$ & $43.0(40.8-45.3)$ \\
\hline
\end{tabular}

Prevalence in \% (estimated $95 \%$ confidence interval); a $95 \%$ Cls of estimates in the Roma child population and in the general child population do not overlap.

\section{Smoking and Alcohol Consumption}

Almost one-quarter of Roma children $(29.6 \%$ of boys and $19.7 \%$ of girls) and about $14 \%$ of children in the general population had tried smoking at age 11 (Table 3). The prevalence of trying tobacco was doubled at age 13 among Roma children.

Further analysis of children's smoking habits showed that most of the children in both populations had never smoked either at age 11 or age 13. In both populations there are more boys who had tried smoking at age 11. Substantially more Roma boys smoked occasionally at age 11 than non-Roma children.

Trying alcohol was more prevalent among the Roma boys at age 11 while in drunkenness was no difference between the two groups. However, in both population groups and in both age groups, more boys than girls reported trying both alcohol and experiencing drunkenness.

\section{Self-rated Health}

The self-rated health status of the Roma children was worse than the self-rated health status of children in the general population. More children in the general population reported excellent or good health, and in both age groups, more than twice as many Roma children reported fair and poor health.

\section{DISCUSSION}

Poor health condition among the Roma population is a welldocumented fact in central European countries, although studying the Roma minority entails some difficulties, e.g. determining the population, accessing the population, and dealing with their high illiteracy rate $(10-13,30)$. In Hungary, a comprehensive survey was performed regarding the health status of the adult Roma population (13).

Roma families, particularly families living in settlements, are more strongly affected by poverty and social deprivation than the average population because of their low education level and high unemployment rate (31). Recently, an increasing number of papers have focused on health status and health behaviours of this socially and economically disadvantaged group $(19,32-34)$. These studies have mainly focused on isolating behavioural characteristics, while only a few studies carried out comprehensive surveys. One study showed a higher prevalence of daily alcohol consumption, drug use and smoking among Roma children (32), while another one found lower prevalence of smoking, drunkenness, drug use and higher rate of physical activity among Roma adolescent girls and lower rate of drug use among Roma adolescent boys, but there was no significant difference in other risk factors (19).

Our comparative study demonstrated that children living in Roma settlements have many unfavourable health behaviour indicators compared with the general youth population mainly at the age 11. Similar findings were reported in other reports (32-34). The self-rated health status of Roma children was worse than that of the children in the general population. The unhealthy eating habits of Roma children were characterized by high consumption of sweets and soft drinks and lower everyday consumption of fruit among girls aged 11 years. The high prevalence of those Roma girls who do not pursue intense physical activity may have resulted in the higher proportion of obesity in both age groups. Our findings seem to contradict some previous results that showed a higher proportion of underweight among Roma children compared to the non-Roma population $(34,35)$. However, the age groups 


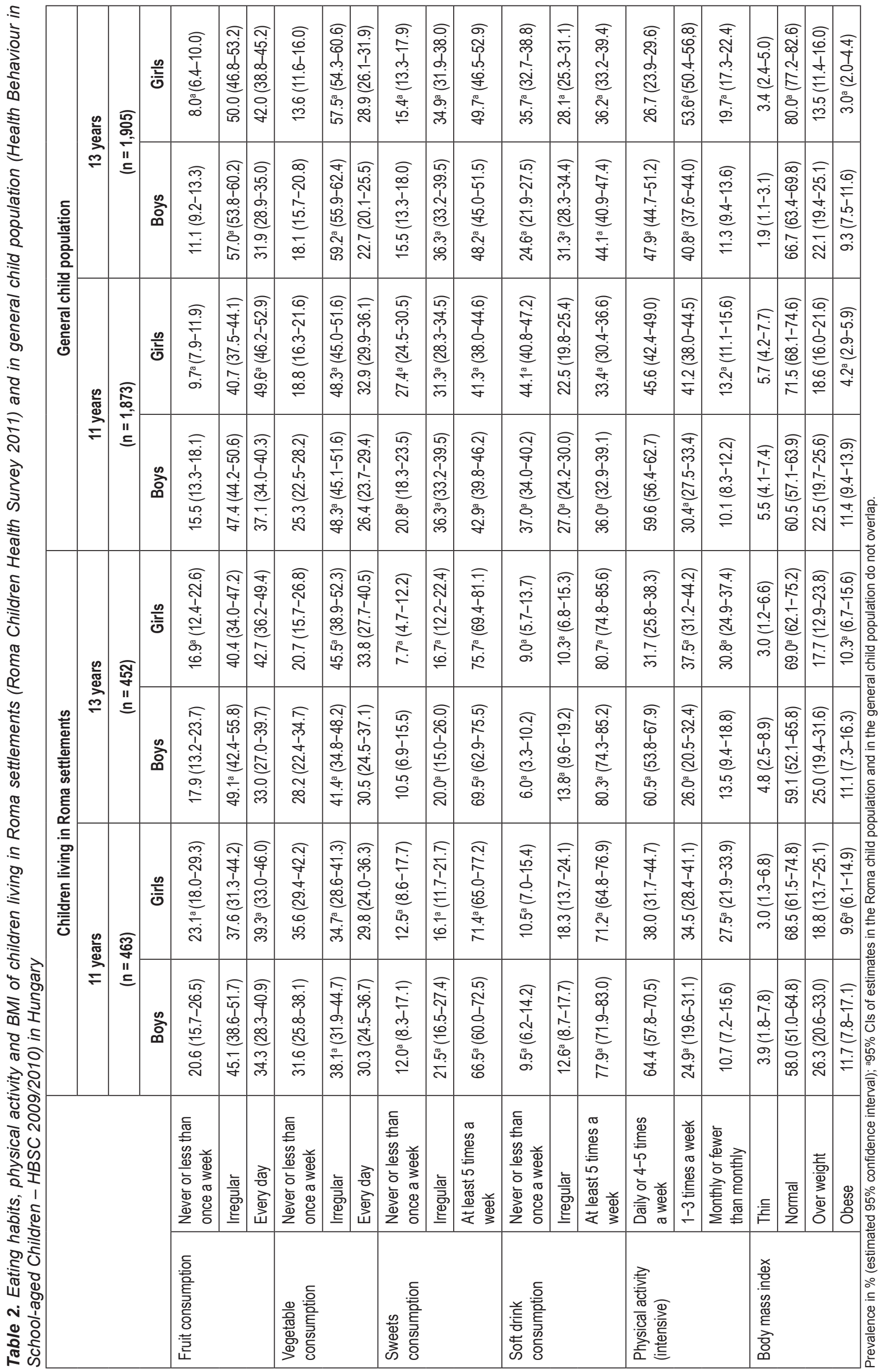


in these surveys were predominantly younger than in our study and our results can be explained by a high intake of carbohydrate foods in this group. Another survey from Canada also showed a high prevalence of overweight and obesity among multi-ethnic schoolchildren in a low-income inner-city neighbourhood (36).

Risk behaviours of Roma children were worse in case of trying tobacco and alcohol than those of the general population. In line with the previous study from Lithuania (32) we revealed a substantially higher prevalence of smoking initiation in both sexes and a higher proportion of trying alcohol among Roma boys. The prevalence of regular smokers was low in both populations, substantially more Roma boys smoked occasionally at age 11 compared to boys in the general population. The prevalence of trying alcohol was also higher among Roma children at age 11 , while we have not found a difference in case of drunkenness between the two groups. These findings clearly show that Roma children try alcohol and smoking earlier than the general child population and in the latter age groups this difference can level off for these risk factors. This may serve to explain why Kolarčik observed a lower smoking and drunkenness prevalence among Roma adolescents (mean age was 14.50 years) (21).

A great number of studies proved that there is a strong association between socioeconomic position and health outcomes and that health behaviours contribute to socioeconomic gradient (37). The differences in the health behaviours between the Roma and the general child population can be explained mainly by the socioeconomic status of their parents, e.g. educational level, income, health literacy and unemployment rate which lead to higher unfavourable risk behaviour not only in the adult but also in the child Roma population $(13,14)$.

This study has some limitations. The survey was conducted in three counties of Hungary, which means that the results are not representative for the overall population of Roma children living in Hungary. The national sample involves the same proportion of Roma children as it is found in the Hungarian population. This may lead to a dilution of the true difference when comparing these two groups. The weight and height of students were selfreported which could cause measurement errors. Moreover, the socioeconomic characteristics of the North-East part of Hungary is worse compared to other regions and therefore we may have received different findings if we compared our Roma children to the children living in this region.

The important strength of our study was the use of identical questionnaires in both surveys, which ensures comparability of data. This means that our study was an extension of the HBSC international survey to a special group.

Our study provided evidence for unfavourable health behaviours mainly in consumption of sweets, soft drinks and early trying of tobacco and alcohol by Roma children. This may lead to a high prevalence of harmful lifestyle and poor health among the adult Roma population. For European Union countries it is vital to initiate, enhance and continue special health education and health promotion programmes for this highly disadvantaged group, especially for children. Recently, the issue of public education of Roma children was highlighted in the Decade of Roma Inclusion, which was followed by a document entitled "Roma in the European Union" (38). Studies show that achievement of Roma children who attend pre-school is higher than children who do not attend. In Hungary, a new pilot programme, called 
Sure Start, was launched in 2003 and it was enhanced in 2006 for the early development of pre-school children living in poor environments in which different professionals are involved (39). On the other hand, it is important to increase job opportunities, social support, to provide access to the health care system and to strengthen the inclusion of the Roma people (38).

In conclusion, children living in Roma settlements reported poorer socioeconomic conditions, higher consumption of sweets and soft drinks, earlier smoking and alcohol initiation and worse self-rated health. Basically, there were no differences in fruit or vegetable consumption and BMI between the two populations. Interdisciplinary and multi-sector approaches, special health education and long-term maintenance of health promotional programmes plus social and health promotion programmes are needed to improve the health behaviours of this disadvantaged group.

\section{Acknowledgement}

HBSC was an international study carried out in collaboration with WHO/ EURO. The International Coordinator of the 2009/2010 HBSC study was Candace Currie, University of St. Andrews, Scotland; the Data Bank manager was Oddrun Samdal, University of Bergen, Norway. A complete list of the participating researchers can be found on the HBSC website (http://www.hbsc.org). The authors of this study thank all the schools, health visitors and students who participated in the HBSC surveys. This work was supported by the ETT (grant No192/2009.) and TAMOP (grant No 4.2.1./B-09/1/KONV-2010-0007).

\section{Conflicts of Interests}

None declared

\section{Adherence to Ethical Standards}

The research was approved by the Regional and Institutional Ethics Committee of the University of Debrecen and by the Scientific and Research Ethics Committee of the Medical Research Council.

\section{REFERENCES}

1. European Commission. Communication from the Commission to the European Parliament, the Council, the European Economic and Social Committee and the Committee of the Regions: An EU Framework for National Roma Integration Strategies up to 2020 [Internet]. Brussels: European Commission; 2011 [cited 2018 Apr 10]. Available from: http:// ec.europa.eu/justice/policies/discrimination/docs/com_2011_173_en.pdf.

2. Marmot M, Wilkinson RG. Social determinants of health. Oxford: Oxford University Press; 1999.

3. Commission on Social Determinants of Health. Closing the gap in a generation: health equity through action on the social determinants of health. Final report of the Commission on Social Determinants of Health [Internet]. Geneva: World Health Organization; 2008 [cited 2018 Apr 2]. Available from: http://apps.who.int/iris/bitstream/10665/43943/1/9789241563703 eng.pdf.

4. Kósa K, Daragó L, Ádány R. Environmental survey of segregated habitats of Roma in Hungary: a way to be empowering and reliable in minority research. Eur J Public Health. 2011 Aug;21(4):463-8.

5. Masseria C, Mladovsky P, Hernández-Quevedo C. The socio-economic determinants of the health status of Roma in comparison with nonRoma in Bulgaria, Hungary and Romania. Eur J Public Health. 2010 Oct;20(5):549-54.

6. Škarić-Jurić T, Klarić IM, Narančić NS, Drmić S, Salihović MP, Lauc LB, et al. Trapped between tradition and transition - anthropological and epidemiological cross-sectional study of Bayash Roma in Croatia. Croat Med J. 2007 Oct;48(5):708-19.
7. Decade of Roma Inclusion 2005-2015 [Internet]. [cited 2018 Apr 2]. Available from: https://web.archive.org/web/20120711142344/http:// www.romadecade.org/about.

8. Fésüs G, Östlin P, McKee M, Ádány R. Policies to improve the health and well-being of Roma people: The European experience. Health Policy. 2012 Apr;105(1):25-32.

9. Dolák F, Šedová L, Nováková D, Olišarová V. Approach to prevention of obesity of Roma population in the Region of South Bohemia with focus on selected eating behaviors. Neuro Endocrinol Lett. 2016 Dec;37 Suppl 2:46-51.

10. Kohler IV, Preston SH. Ethnic and religious differentials in Bulgarian mortality, 1993-98. Popul Stud (Camb). 2011 Mar;65(1):91-113.

11. Bogdanović D, Nikić D, Petrović B, Kocić B, Jovanović J, Nikolić M, et al. Mortality of Roma population in Serbia, 2002-2005. Croat Med J. 2007 Oct;48(5):720-6.

12. Ringold D, Orenstein MA, Wilkens E. Roma in an expanding Europe: breaking the poverty cycle. Washington DC: World Bank; 2005.

13. Kósa Z, Széles G, Kardos L, Kósa K, Németh R, Országh S, et al. A comparative health survey of the inhabitants of Roma settlements in Hungary. Am J Public Health. 2007 May;97(5):853-9.

14. Vokó Z, Csépe P, Németh R, Kósa K, Kósa Z, Széles G, et al. Does socioeconomic status fully mediate the effect of ethnicity on the health of Roma people in Hungary? J Epidemiol Community Health. 2009 Jun;63(6):455-60.

15. Rosicova K, Madarasova Geckova A, van Dijk JP, Kollarova J, Rosic M, Groothoff JW. Regional socioeconomic indicators and ethnicity as predictors of regional infant mortality rate in Slovakia. Int J Public Health. 2011 Oct;56(5):523-31.

16. Balázs P, Rákóczi I, Grenczer A, Foley KL. Birth-weight differences of Roma and non-Roma neonates - public health implications from a population-based study in Hungary. Cent Eur J Public Health. 2014 Mar;22(1):24-8

17. Balázs P, Rákóczi I, Grenczer A, Foley KL. Birth-weight of Roma neonates: biomedical and socioeconomic factors in Hungary. Orv Hetil. 155(24):954-62. (In Hungarian.)

18. Kolarčik P, Madarasová Gecková A, Orosová O, van Dijk JP, Reijneveld SA. To what extent does socioeconomic status explain differences in health between Roma and non-Roma adolescents in Slovakia? Soc Sci Med. 2009;68(7):1279-84

19. Kolarčik P, Madarasová Gecková A, van Dijk JP, Reijneveld SA. Predictors of health-endangering behaviour among Roma and non-Roma adolescents in Slovakia by gender. J Epidemiol Community Health. 2010;64:1043-8.

20. Bobakova D, Kolarcik P, Madarasova Geckova A, Klein D, Reijneveld SA, van Dijk JP. Does the influence of peers and parents on adolescents' drunkeness differ between Roma and non-Roma adolescents? Ethn Health. 2012;17(5):531-41.

21. Kolarčik P. Self-reported health and health risky behaviour of Roma adolescents in Slovakia: a comparison with the non-Roma, 2007-2012 [dissertation]. Groningen; 2012.

22. Health Behaviour in School-Aged Children [Internet]. [cited 2018 Apr 3]. Available from: http://www.hbsc.org/about/index.html.

23. Currie C, Zanotti C, Morgan A, Currie D, de Looze M, Roberts C, et al., editors. Social determinants of health and well-being among young people. Health Behaviour in School-Aged Children (HBSC) study: international report from the 2009/2010 survey. Health policy for children and adolescents, no. 6. Copenhagen: WHO Regional Office for Europe; 2012

24. Currie C, Griebler R, Inchley J, Theunissen A, Molcho M, Samdal O, et al., editors. Health Behaviour in School-aged Children (HBSC) study protocol: background, methodology and mandatory items for the 2009/10 survey. Edinburgh: CAHRU; 2010.

25. Németh Á, Költö A, editors. Health status and health behaviour of adolescents 2010. Health Behaviour in School-aged Children (HBSC): a WHO-collaborative cross-national study national report. Budapest: National Institute of Child Health; 2011. (In Hungarian.)

26. Roberts C, Freeman J, Samdal O, Schnohr C, Looze M, Nic Gabhainn $\mathrm{S}$, et al.; HBSC Methods Development Group. The Health Behaviour in School-aged Children (HBSC) study: methodological developments and current tensions. Int J Public Health. 2009;54 Suppl 2:140-50.

27. Currie C, Molcho M, Boyce W, Holstein B, Torsheim T, Richter M. Researching health inequalities in adolescents: The development of the Health Behaviour in School-Aged Children (HBSC) family affluence scale. Soc Sci Med. 2008 Mar;66(6):1429-36. 
28. de Onis M, Onyango AW, Borghi E, Siyam A, Nishida C, Siekmann J. Development of a WHO growth reference for school-aged children and adolescents. Bull World Health Organ. 2007 Sep;85(9):660-7.

29. WHO. Growth reference 5-19 years [Internet]. [cited 2018 Apr 10]. Available from: http://www.who.int/growthref/who2007_bmi_for_age/ en/.

30. Šedová L, Tóthová V, Olišarová V, Adámková V, Bártlová S, Dolák F, et al. Evaluation of selected indicators of overweight and obesity of Roma minority in the region of South Bohemia. Neuro Endocrinol Lett. 2015;36 Suppl 2:35-42.

31. European Commission. The Situation of Roma in an enlarged European Union. Luxembourg: Office for Official Publications of the European Communities; 2005.

32. Kanapeckienė V, Valintėlienė R, Beržanskytė A, Kèvalas R, Supranowicz P. Health of Roma children in Vilnius and Ventspils. Medicina (Kaunas). 2009;45(2):153-61.

33. Hujova Z, Alberty R, Paulikova E, Ahlers I, Ahlersova E, Gabor D, et al. The prevalence of cigarette smoking and its relation to certain risk predictors of cardiovascular diseases in central-Slovakian Roma children and adolescents. Cent Eur J Public Health. 2011 Jun;19(2):67-72.

34. Janevic T, Petrovic O, Bjelic I, Kubera A. Risk factors for childhood malnutrition in Roma settlements in Serbia. BMC Public Health. 2010 Aug 22;10:509. doi: 10.1186/1471-2458-10-509.
35. Spiroski I, Dimitrovska Z, Gjorgjev D, Mikik V, Efremova-Stefanoska V, Naunova-Spiroska D, et al. Nutritional status and growth parameters of school-age Roma children in the Republic of Macedonia. Cent Eur J Public Health. 2011 Jun;19(2):102-7.

36. O'Loughlin J, Paradis G, Renaud L, Meshefedjian G, Gray-Donald K. Prevalence and correlates of overweight among elementary schoolchildren in multiethnic, low income, inner-city neighbourhoods in Montreal, Canada. Ann Epidemiol. 1998 Oct;8(7):422-32.

37. Petrovic D, de Mestral C, Bochud M, Bartley M, Kivimäki M, Vineis P, et al. The contribution of health behaviors to socioeconomic inequalities in health: A systematic review. Prev Med. 2018 Aug;113:15-31.

38. European Parliament. Roma in the European Union. European Parliament resolution on the situation of Roma in the European Union [Internet]. Brussels: European Parliament; 2005 [cited 2018 Apr 15]. Available from: http://www.europarl.europa.eu/sides/getDoc.do?pubRef=-//EP// NONSGML+TA+P6-TA-2005-0151+0+DOC+PDF+V0//EN .

39. Danis I, Farkas M, Herczog M, Szilvási L. From genes to society: the scenes of early childhood development. Budapest: Nemzeti Család- és Szociálpolitikai Intézet; 2011. (In Hungarian.)

Received February 12, 2016 Accepted in revised form January 30, 2019 